\title{
Analysis of the risk factors and microbial etiology of surgical site infections following Lower Segment Caesarean Section
}

\author{
A Shrestha ${ }^{a}$, N Pradhan ${ }^{b}$
}

\begin{abstract}
Background

Lower segment caesarean section (LSCS) is a common surgical mode of delivery and surgical site infection is the most common infectious complication in these patients. The main objective of the study was to analyse the risk factors and microbial etiology of surgical site infection (SSI) following LSCS.

\section{Methods}

300 consecutive patients undergoing LSCS, irrespective of indication, were studied. A questionnaire was developed to assess the risk factors associated with development of SSI. All patients were followed up from day one of surgery till discharge and then up till 45 days following LSCS.
\end{abstract}

\begin{abstract}
Results
SSI was identified in 78 (22.66\%) out of 300 patients. $5.11 \%$ of Staphylococcus aureus. strains were MRSA. The Acinetobacter species (32.03\%) was the most common organisms isolated followed by Staphylococcus aureus $(20.41 \%)$ and Coagulase negative staphylococcus (13\%). Premature rupture of membrane (PROM) of more than 4 hours, Emergency LSCS, anaemia and increase in adipose tissues were the commonest risk factors.

\section{Conclusions}

A proper assessment of risk factors that pre-dispose to SSI and their early detection and modification may help in reduction of SSI rates. Also, antimicrobial audit and infection surveillance could give an insight into the current antibiotic prescription practices.
\end{abstract}

Key words: Lower segment caesarean section, risk factors, surgical site infection.

Sri Lanka Journal of Obstetrics and Gynaecology

2019; 41: 15-19

DOI: http://doi.org/10.4038/sljog.v41i1.7828

${ }^{a}$ Associate Professor and Consultant in Obstetrics and Gynaecology, Department of Obstetrics and Gynaecology, Dhulikhel Hospital, Kathmandu University Hospital, Katmandu.

${ }^{\mathrm{b}}$ Lecturer in Obstetrics and Gynaecology, Department of Obstetrics and Gynaecology, Dhulikhel Hospital, Kathmandu University Hospital, Katmandu.

Correspondence: AS, e-mail: <abhaobgy@gmail.com>

Received $1^{\text {st }}$ December 2018 and revised version accepted $6^{\text {th }}$ March 2019.

iD http://orcid.org/0000-0002-8465-0590

Competing interest: The authors report no conflict of interest

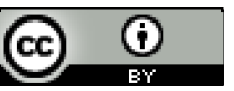

This is an open-access article distributed under the terms of the Creative Commons Attribution 4.0 International License, which permits unrestricted use, distribution and reproduction in any medium provided the original author and source are credited. 


\section{Introduction}

Cesarean section is the commonest major Obstetrical operation. The incidence of LSCS is rising over the past decade in Nepal. Surgical site infection (SSI) is a common, postoperative complication that causes considerable morbidity. SSI is an important factor and carries 5-10 fold increased risk of postpartum infection compared to vaginal delivery. ${ }^{1}$ We have not come across many studies done in Nepal regarding surgical site infection following LSCS. As a result not much data is available on the incidence rates of SSI following lower segment cesarean section in Nepali hospitals. The data is also lacking in the knowledge of common pathogens after LSCS. There exists a need to investigate intra-operative and postoperative risk factors for SSI after LSCS. In spite of the availability of antibiotics, SSI increases the morbidity and also increase the hospital stay and cost. SSIs are still responsible for much morbidity and socioeconomic burden for both patients as well as health care systems. ${ }^{2}$ Reduction in surgical site infections while minimizing antibiotic resistance still remains a challenge for many health care institutions. ${ }^{3}$ So, the main aim of our study is to analyse the risk factors and microbial etiology of surgical site infection (SSI) following LSCS.

\section{Materials and Methods}

This is a prospective study done in the Department of Obstetrics and Gynaecology, Dhulikhel Hospital. Kathmandu University Hospital, Nepal from 2015 March to January 2017. 300 consecutive patients undergoing emergency/elective LSCS were included in the study irrespective of the indication. During this period 5721 deliveries were conducted. The patients were assessed preoperatively and also postoperatively on $3^{\text {rd }}$ post operative day as well as on $45^{\text {th }}$ post operative day, which matches with their post natal visit as well as immunization of the baby. Informed consent was taken from every patient enrolled in the study. LSCS wound was inspected at the time of dressing on the third postoperative day and also on the day of discharge of the patient and then all patients were followed up in postnatal clinic till the $45^{\text {th }}$ postoperative day. All patients who developed SSI following surgery were included as cases. Data was collected from every patient regarding the various risk factors and demographic details by means of a detailed questionnaire.

Surgical site infection was detected on the basis of the criteria given in the modified CDC (Centres for Disease Control and Prevention) definition. ${ }^{4}$ Purulent discharge was collected from the surgical incision site with sterile cotton swabs. Blood sample for blood culture and urine culture were collected as and when the possibility of septicemia or bacteremia was suspected, as suggested by the presence of fever, shock, or other signs and symptoms of sepsis associated with the surgical wound. The bacterial isolates obtained were identified as per standard identification procedures. ${ }^{5}$ Antibiotic susceptibility of the incriminated organism was done using standard disc diffusion method as per Clinical Laboratory Standards Institute guidelines. ${ }^{6}$ Data was recorded on a questionnaire and managed on Microsoft excel 2007 software. The data were analysed as frequency and percentage.

\section{Results}

Amongst 300 women, included in the study most of them were in the age group of 21-25 years. The mean age of patients who underwent LSCS was $23 \pm 3.6$ years. $183(61 \%)$ patients were in the age group of 21-25 years, followed by the age group of 26-30 years $(30 \%)$. Only $3(8 \%)$ were more than 35 years of age as shown in table 1 . No women were less 18 years.

\section{Table 1. Age distribution of women undergoing LSCS}

\begin{tabular}{|l|c|c|}
\hline Age & Number & Percentage \\
\hline $18-20$ & 22 & 7.34 \\
$21-25$ & 183 & 61 \\
$26-30$ & 90 & 30 \\
$31-35$ & 3 & 1 \\
$>35$ & 2 & 0.66 \\
\hline Total & 300 & 100 \\
\hline
\end{tabular}

$262(87.3 \%)$ out of 300 women underwent emergency LSCS while only $38(12.6 \%)$ women underwent elective surgery. 78 (22.66\%) women had surgical site infection following LSCS of them 56 (18.66\%) women were found to have infection at the surgical site during their stay in the hospital within 5 days of surgery. $22(7.3 \%)$ women with surgical site infection detected within 45 post operative day, when they came for follow up. A total of 78 bacterial isolates were obtained. 9 (3\%) SSIs had a polymicrobial etiology. Acinetobacter species was the most common isolate 19 (24.4\%) followed by Staphylococcus aureus $16(20.41 \%)$ and Coagulase negative Staphylococcus $10(13 \%)$ as shown in table 2 . 
Table 2. Type of bacterial isolates

\begin{tabular}{|l|c|c|}
\hline Type of bacterial isolates & Number & Percentage \\
\hline Acinetobacter & 19 & 24.4 \\
Staphylococcus aureus & 16 & 20.41 \\
Coagulase negative Staphylococcus & 10 & 13 \\
Escherichia coli. & 9 & 11.5 \\
Polymicrobial & 9 & 11.53 \\
Enterococcus & 5 & 6.41 \\
Methiciilin resistant Staphylococcus aureus (MRSA) & 4 & 5.11 \\
Klebsiella & 3 & 3.8 \\
Psedomonas & 2 & 2.56 \\
Proteus & 1 & 1.28 \\
\hline Total & 78 & 100 \\
\hline
\end{tabular}

Amongst 78 women who had SSI, 72 (92.30\%) had undergone Emergency LSCS compared to Elective LSCS 6 $(7.69 \%)$. Other significant risk factors were Premature rupture of membrane (PROM) $>6$ hours, maternal adiposity, anemia as shown in table 3 .

Table 3. Risk factors for surgical site infection (SSI)

\begin{tabular}{|l|c|c|}
\hline Risk factors & Number & Percentage \\
\hline Premature rupture of membrane $>6$ hours & 37 & 47.43 \\
Maternal adiposity & 19 & 24.35 \\
Maternal anaemia & 11 & 14.13 \\
Preoperative fever & 8 & 10.25 \\
Preclampsia & 2 & 2.56 \\
Overt diabetes & 1 & 1.28 \\
\hline Total & 78 & 100 \\
\hline
\end{tabular}

\section{Discussion}

Surgical site infection is an important outcome indicator after surgery. The situation is worsened by the emergence of polymicrobial resistant strains of nosocomial pathogens and Methicillin resistant Staphylococcus. ${ }^{7}$ In our study we had 9 patients with polymicrobial infection. This also increases morbidity significantly as it prolongs the hospital stay of patients.
According to a study by ward et $\mathrm{al}^{8} 7-12 \%$ of hospitalized patients end up with hospital acquired infections globally with more than 1.4 million people suffering from infectious complications acquired in the hospital. The infection rate in the present study was $22.66 \%$ including post discharge surveillance and it is similar to a study by Cardosodel et $\mathrm{al}^{9}$ who reported a rate of $23.5 \%$. 
Emergency LSCS predisposes more to SSI as compared to elective surgery. ${ }^{10}$ In the present study, out of 300 patients, $87.3 \%$ women underwent emergency LSCS and similar findings of SSI was observed. The reason in our case could be many women who underwent Emergency LSCS were referred cases, who had ruptured membranes at home or in health centers or who had attempted home delivery and this predisposes the women to increased exogenous bacterial contamination as there is lack of use of sterile technique or timely antibiotic prophylaxis. Similar findings have been reported by Martens et al. ${ }^{11}$

Body mass index of more than 25 has been shown to affect the outcome of surgery. The local changes such as increase in adipose tissue, a need for larger incision, decreased circulation to fat tissue, and an increase in local tissue trauma related to retraction contribute to an increased incidence of SSI in these patients. ${ }^{12}$ Independent factors related to body homeostatic balance which take place in wound healing and immune function are disturbed in such patients. In the present study an increased BMI was seen to influence the outcome of surgery in terms of an increased rate of infection like other study. ${ }^{12}$

Patients with anaemia were seen to be more prone to SSI. Anaemia diminishes resistance to infection and is frequently associated with puerperal sepsis. Preoperative anaemia is an important predictor of infection and has been proved by several other studies. ${ }^{13}$ In our study also, anaemia was found to be significantly associated with SSI. Premature rupture of membranes is associated with the largest bacterial inoculum and liquor gets infected and infection supervenes. ${ }^{14} \mathrm{We}$ did not find any association between the type of incision made and surgical site infection. Antibiotic prophylaxis in surgical patients has always been a matter of debate. For prophylactic antibiotic the current recommendation states that the parenteral antibiotic must be given 30 minutes prior to the incision so as to attain high tissue and serum levels during surgery ${ }^{15}$. As per the hospital policy Inj Ceftriaxone was administered, those who received antibiotics before surgery were found to be less prone to SSI as compared to those who did not receive it. Some received it just before the incision as it was an emergency case.

Shapiro et $\mathrm{al}^{16}$ reported that with each hour of surgery the infection rate almost doubles. The finding relates to the pharmacokinetics of the antibiotic prophylaxis and to the greater bacterial wound contamination that occurs in lengthy clean-contaminated surgeries. In the present study, $65 \%$ of patients with prolonged duration of surgery exceeding 45 minutes got infected. A prolonged preoperative stay in the hospital due to conditions like urinary tract infection, respiratory tract infection or blood pressure management, have been shown to increase the rate of SSI. ${ }^{3}$ In our study patients who had $>3$ sterile vaginal examination did not show increased rate of SSI, it may be because that all such patients had received a timely antibiotic prophylaxis. The postoperative stay was longer in patients who developed SSI as shown in a study by Lilani et al. ${ }^{17}$ Patients with preexisting illnesses like overt diabetes mellitus, preclampsia were more prone to infection in the present study. Hyperglycaemia has several deleterious effects upon host immune function, most notably on neutrophil function. Poor control of glucose during surgery and in the perioperative period increases the risk of infection and worsens outcome from sepsis. Hypertension, preexisting or pregnancy induced, HIV, and other comorbid states have been associated with SSI in several studies. ${ }^{18,19}$ Studies have shown that common causative organisms leading to post-LSCS SSI include Gram-negative bacteria, anaerobes, and Staphylococcus aureus. ${ }^{20}$ In our study, predominant micro organism was Staphylococcus aureus $(38.5 \%)$ which included Coagulase negative Staphylococcus aueus and MRSA and followed by Acinetobacter species $(24.4 \%)$. Many other studies have reported similar findings of predominance of Staphylococcus aureus in wound infections. ${ }^{21}$ Polymicrobial etiology was found in 9 out of 78 SSIs identified. Lilani et al. found a polymicrobial etiology in 2 out of 7 SSIs. One of the most prevalent bacteria isolated was Staphylococcus aureus. Special interest in Staphylococcus aureus SSI is due to its role in hospital infection and MRSA infections are of great concern due to high morbidity and mortality rates. Staphylococcus aureus originates from patients' nasal flora and may influence the outcome of surgery. ${ }^{22}$ The increased isolation rates of Staphylococcus aureus stresses the need to screen and treat subjects for nasal carriage which could possibly influence etiology of SSIs.

\section{Limitation}

It would have been more significant if it had been a multicentre trial involving many tertiary hospitals like ours.

\section{Conclusion}

A proper assessment of risk factors that predispose to SSI and their early detection is important in our context 
as it helps in the modification of risk factors and also helps in reduction of SSI rates. Also, antimicrobial audit and infection surveillance could give an insight into the current antibiotic prescription practices.

\section{References}

1. Chaim W, Bashiri A, Bardavid J, Shoham-Vardi I, Mazor M. Prevalence and clinical significance of postpartum endometritis and wound infection. Infect Dis Obstet Gynecol 2000; 8(2): 77-82.

2. Berg CJ, Chang J, Callagahan WM, Whitehead SJ. Pregnancy related mortality in the United States.1991-1997. Obstet Gynecol 2003;10: 289-96.

3. De D, Saxena S, Mehta G, Yadav R, Dutta R. Risk Factor Analysis and Microbial Etiology of Surgical Site Infections following Lower Segment Caesarean Section. Intl. J. Antibiot. 2013: 6.

4. Horan TC, Gaynes RP, Martone WJ, Jarvis WR, Emori TG. CDC definitions of nosocomial surgical site infections: a modification of CDC definitions of surgical wound infections. Infection Control and Hospital Epidemiology.1992; 13: 606-8.

5. Collee JG, Marr W. Culture of bacteria. Mackie \& McCartney Practical Medical Microbiology. 1996; 14: 113-29, Churchill Livingstone, Elsevier.

6. Mathew A, Franklin R, William A. Performance standards for antimicrobial susceptibility testing. Clinical and Laboratory Standards Institute. 2006; 26: $16 \mathrm{r}$.

7. Kamat. UA, Savio FR, Motghare D. Antimicrobial resistance among nosocomial isolates in a teaching hospital in Goa. Indian J Community Med. 2008; 33: 89-92.

8. Ward VP, Charlett A, Fagan J, Crawshaw SC. Enhanced surgical site infection surveillance following caesarean section: experience of a multicentre collaborative post-discharge system. J Hosp Infect. 2008; 70: 166-73.

9. Cardoso MC, Pinto AM. Post discharge surveillance following cesarean section for incidence of surgical site infection and associated factors. Am J Infections Control. 2010; 38(6): 467-72.

10. Obstetric and medical complications. American College of Obstetricians and Gynecologists.
Guidelines for perinatal care. $6^{\text {th }}$ ed. Elk Grove Village IL. 2007: 175-204.

11. Martens MG, Kolrud BL, Faro S, Maccato M, Hammill H. Development of wound infection or separation after cesarean delivery: prospective evaluation of 2,431 cases. J Reprod Med 1995; 40: (3) 171-5.

12. Ghuman M, Rohlandt D, Joshy G, Lawrenson R. Post-caesarean section surgical site infection: rate and risk factors. N Z Med J. 2011; 124(1339): 32-6.

13. Malone DL, Genuit T, Tracy JK, Gannon C, Napolitano LM. Surgical site infections: reanalysis of risk factors. J Surg Res. 2002; 103(1): 89-95.

14. Dhar H, Ibrahim A, Rathi B, Nimre EA, Sachdeva.V, Hamdi I. A Study of Post-Caesarean Section Wound Infections in a Regional Referral Hospital, Oman. Sultan Qaboos Univ Med J. 2014; 14(2): 211-21.

15. Woods RK, Dellinger P. Current Guidelines for Antibiotic Prophylaxis of Surgical Wounds. Am Fam Physician. 1998; 57(11): 2731-40.

16. Shapiro M, Munoz A, Tager IB. Risk factors for infection at the operative site after abdominal or vaginal hysterectomy. Nejm 1982; 307(27): 1661-6.

17. Lilani SP, Jangale N, Chowdhary A, Daver GB. Surgical site infection in clean and cleancontaminated cases. Indian J. Med. Microbiol. 2005; 23(4): 249-52.

18. Kofman NS, Sheiner E, Levy A, Holcberg G. Risk factors for wound infection following cesarean deliveries. Int J Gynecol Obstet. 2005; 90(1): 10-15.

19. Kirby JP, Mazuski E. Prevention of surgical site infection. Surg Clin North Am. 2009; 89(2): 365-89.

20. Cunningham FG, Dorsten JP, Eds. Operative Obstetrics, McGraw Hill, New York, NY, USA, 2 ed, 2002.

21. Olson MM, Lee JT. Continuous 10-year wound infection surveillance. Results, advantages, and unanswered questions. Arch Surg. 1990; 125 (6): 794-803.

22. Walsh C, Scaife C, Hopf H. Prevention and management of surgical site infections in morbidly obese women. Am J Obstet Gynecol. 2009; 113(2): 411-41. 